\title{
Poor physical function in elderly women in low-level aged care is related to muscle strength rather than to measures of sarcopenia
}

This article was published in the following Dove Press journal:

Clinical Interventions in Aging

22 March 20II

Number of times this article has been viewed

Julie L Woods'

Sandra Iuliano-Burns ${ }^{2}$

Susannah J King'

Boyd J Strauss'

Karen Z Walker'

'Nutrition and Dietetics Department, Monash University, Victoria, Australia; ${ }^{2}$ Endocrine Centre of Excellence, Department of Medicine, Austin Health, University of Melbourne, West Heidelberg, Australia
Correspondence: Karen Z Walker Nutrition and Dietetics Department, Monash University, Level 5, Block E, Monash Medical Centre, 246 Clayton Rd, Clayton, Victoria, Australia, 3168

Tel +6I 395947516

Fax +6I 395946509

Email karen.walker@monash.edu
Purpose: To determine the prevalence of sarcopenia and investigate relationships among body composition, muscle strength, and physical function in elderly women in low-level aged care.

Subjects and methods: Sixty-three ambulatory women (mean age 86 years) participated in this cross-sectional study where body composition was determined by dual energy X-ray absorptiometry (DXA); ankle, knee, and hip strength by the Nicholas Manual Muscle Tester; and physical function by 'timed up and go' (TUG) and walking speed (WS) over 6 meters. Body composition data from a female reference group $(n=62$, mean age 29 years $)$ provided cut-off values for defining sarcopenia.

Results: Elderly women had higher body mass index $(P<0.001)$, lower lean mass $(P<0.001)$, and higher fat mass $(P<0.01)$ than the young reference group. Only a small proportion $(3.2 \%)$ had absolute sarcopenia (defined by appendicular skeletal muscle mass/height squared) whereas $37 \%$ had relative sarcopenia class II (defined by percentage skeletal muscle mass). Scores for TUG and WS indicated relatively poor physical function, yet these measures were not associated with muscle mass or indices of sarcopenia. In multivariate analysis, only hip abductor strength predicted both TUG and WS (both $P=0.01$ ).

Conclusion: Hip strength is a more important indicator of physical functioning than lean mass. Measurement of hip strength may therefore be a useful screening tool to detect those at risk of functional decline and requirement for additional care. Further longitudinal studies with a range of other strength measures are warranted.

Keywords: aged care, body composition, muscle strength, sarcopenia

\section{Introduction}

Body composition changes with aging, even in relatively healthy elderly. From middle adulthood, height declines, while body weight initially increases, then also declines from around the age of 65 years. ${ }^{1,2}$ These body weight changes reflect changes in body composition. After middle age fat mass (FM) gradually increases while lean tissue mass (LTM) decreases. ${ }^{3,4}$ Marked age-related loss of skeletal muscle mass (SMM) is known as sarcopenia and is associated with loss of strength, functional impairment, and disability. ${ }^{5,6}$

Sarcopenia has proved difficult to define. Baumgartner ${ }^{7}$ used absolute terms, defining sarcopenia as present when appendicular skeletal muscle mass (ASM) normalized for (height $)^{2}$ falls below two standard deviations (SD) of the sex-specific mean for a young adult reference population. In contrast, Janssen ${ }^{8}$ used relative terms, defining sarcopenia as $\%$ SMM adjusted for weight and using cut points ( $<1$ or $<2 \mathrm{SD}$ ) drawn relative to the sex-specific mean of a young adult reference group. By either method, sarcopenia 
is independently associated with self-reported functional impairment and physical disability. ${ }^{7,8}$

As SMM declines with aging, muscle strength also decreases. ${ }^{9}$ This relationship is nonlinear so that over time, the strength decline exceeds the decline in SMM by a factor of $3: 1,{ }^{9}$ and SMM no longer closely reflects muscle strength. ${ }^{9-11}$ The question therefore arises as to whether muscle strength is a more important determinant of physical function and disability than the quantity of $\mathrm{SMM}^{12,13}$ in elderly women.

To date, most studies on body composition and physical function in the elderly have focused on healthy, community dwelling individuals. ${ }^{7-9,11-13}$ Few have investigated institutionalized elderly who, by virtue of their need for care, are more likely to exhibit sarcopenia and physical impairment than their community dwelling counterparts. ${ }^{14}$ In Australia, one in three who live in aged care accommodation reside in low-level care facilities. ${ }^{15}$ Despite their semi-independent status, relative mobility, and capacity for self-care, there is a high prevalence of malnutrition, ${ }^{16}$ which is a risk factor for sarcopenia. ${ }^{5}$ Moreover, the detection of sarcopenia and/ or reduced muscle strength in these elderly is important as a predictor of morbidity risk and need for higher level care. ${ }^{17}$

Physical function in elderly people has been assessed by the timed 'up and go' test (TUG), and by walking speed over 6 meters (WS). TUG is considered a satisfactory measurement of balance in the elderly, ${ }^{18}$ while WS is reflective of general well being. ${ }^{19}$ Both measures are more objective than the self-reported activity measures frequently used in studies in the elderly ${ }^{18}$ and both have well established risk identification cut points. ${ }^{19-22}$ The objectives of this study were to measure body composition by the optimal measure of dual energy X-ray absorptiometry (DXA), ${ }^{23}$ in elderly Australian women living in low-level care accommodation; to determine the prevalence of sarcopenia (defined in absolute or relative terms) and to investigate relationships among body composition, muscle strength, and physical function.

\section{Materials and methods}

\section{Study design and participants}

Participants were Caucasian women residing in low-level aged care facilities in metropolitan Melbourne, Australia. Low-level care caters for semi-independent ambulatory elderly who are 'relatively healthy', as distinct from highlevel care which caters for those with severe chronic illness and/or disability. ${ }^{24}$ An assessment of medical, physical, social, and psychological needs is first made to determine eligibility for entrance to care. Low-level care facilities in Australia typically provide a lower level of nursing support and provide fewer allied health services such as physiotherapy and podiatry relative to high-level care. Data were obtained at the initial assessment of elderly women from 14 low-level aged care hostels who were recruited into a two-year cluster randomized control trial. ${ }^{16}$ Women were enrolled if they were ambulatory and able to self-feed. Women were excluded only if they were non-Caucasian or unable to communicate in English. As a consequence of their residential status, all received considerable assistance with daily activities whether this was required or not. While 78 women were recruited, this study consists of the 63 women for whom DXA data were complete. The 15 women with missing data were of similar age and body mass index (BMI) to those studied (data not shown). The study was approved by the Human Research Ethics Committee, Austin Health and by the Standing Committee on Ethics in Research involving Humans, Monash University.

\section{Young adult reference group}

As there are no published standard values for body composition for Australian adults, and no single set of accepted definitions for sarcopenia, local reference population data were acquired and used to determine cut-off values for sarcopenia. Data were obtained from 62 apparently healthy, nonsmoking Caucasian women aged $18-40$ years and with BMI $17.9-35.4 \mathrm{~kg} / \mathrm{m}^{2}$ who were recruited from the local community. ${ }^{25}$ Their body composition was determined by DXA as described also for the elderly female cohort (see below). Young women were excluded from this reference group if they currently smoked, were non-Caucasian, had a history of reduced bone mineral density or osteoporotic fractures, had used oral or intravenous corticosteroids, or were pregnant.

\section{Muscle strength assessment}

Muscle strength was assessed by an objective method: determination of the maximal isometric strength of the ankle dorsiflexers, knee extensors, and hip abductors on both legs using a hand held dynamometer - the Nicholas Manual Muscle Tester (NMMT; Lafayette Instruments, Lafayette, IN) ${ }^{26}$ One experienced technician (BK) performed all strength assessments on 53 elderly women. Women with missing data were of similar age and body composition (data not shown). The NMMT quantifies the breaking force (in $\mathrm{kg}$ ) necessary to depress a limb when held in a specific position. Each muscle group on the right and left legs was assessed in two separate trials and the average maximal force observed at each site was used for analysis. Each average maximal force (in $\mathrm{kg}$ ) was multiplied by 9.81 to convert it to newtons $(\mathrm{N})$, then divided by body 
weight $(\mathrm{kg})$ to provide a measure of isometric strength $(\mathrm{N} / \mathrm{kg}){ }^{27}$ The intraclass correlation coefficient of all measures was above $0.93(P<0.001)$, indicating high reproducibility. ${ }^{28}$

Isometric strength testing measures static muscle force and does not take into account dynamic muscle performance which includes muscle work, muscle power, and muscle impulse, as in isokinetic strength measurement. Hence, isometric strength does not necessarily reflect the strength an individual might exhibit in a dynamic test. ${ }^{29}$ However, isometric strength testing of the lower extremity, using a hand held device has been found to be both reliable and valid in older people. ${ }^{30}$

\section{Assessment of physical function}

Physical function was determined by TUG and WS over a $6 \mathrm{~m}$ distance as described by Hill et al. ${ }^{26}$ TUG reflects the time in seconds taken to stand from a seated position, walk $3 \mathrm{~m}$, turn around, walk back, and sit down again. To determine WS, women walk at a comfortable speed over $8 \mathrm{~m}$ while the time taken (in seconds) to walk the central $6 \mathrm{~m}$ is recorded. A walking speed ( $\mathrm{m} / \mathrm{second})$ is then calculated. One technician $(\mathrm{BK})$ performed all function tests.

\section{Anthropometry}

Body weight was measured to $\pm 0.1 \mathrm{~kg}$ on an electronic scale (SECA, Hamburg, Germany) with participants wearing light indoor clothing and no shoes. Standing height was measured using a stadiometer (Holtain, Crosswell, UK). BMI was calculated as weight divided by height squared $\left(\mathrm{kg} / \mathrm{m}^{2}\right)$. Underweight was defined as BMI $<20 \mathrm{~kg} / \mathrm{m}^{2}$, normal weight as BMI $20-24.9 \mathrm{~kg} / \mathrm{m}^{2}$, overweight as BMI $25-29.9 \mathrm{~kg} / \mathrm{m}^{2}$, and obesity as BMI $>30 \mathrm{~kg} / \mathrm{m}^{2}$. In Figure 1, BMI $<25 \mathrm{~kg} / \mathrm{m}^{2}$ is described as 'lean'.

\section{Dual-energy X-ray absorptiometry}

Elderly participants and the young reference population underwent whole body DXA scans to provide estimates of LTM and FM (Prodigy, Version 7.51; GE Lunar, Madison, WI and DPX-IQ, software version 4.7e; Lunar Radiation Corporation, Madison, WI, respectively) using the standardized procedures of the manufacturer. These machines provide similar measures of body composition. ${ }^{31-33}$ Calibration against a standard block was performed daily, while precision monitoring against a standard lumbar spine bone mineral density phantom was undertaken weekly. No systematic long-term bias was evident in the phantom data. DXA scans were analysed by a single radiographer for each study group. Appendicular skeletal muscle mass (ASM) was calculated from the sum of LTM for the arms plus legs. ${ }^{34}$ Total skeletal muscle mass (SMM) was determined from ASM using the predictive equation of Kim:

Total SMM $(\mathrm{kg})=(1.13 \times \mathrm{ASM})-(0.02 \times$ age $)+$ $(0.61 \times \operatorname{sex})+0.97$

where sex $=0$ for females. ${ }^{35}$

\section{Body composition indices}

To determine absolute sarcopenia, ASM was adjusted for stature (ASM/height squared $\left.\left(\mathrm{kg} / \mathrm{m}^{2}\right)\right) .{ }^{7}$ Percentage skeletal muscle $(\mathrm{SMI} \%)$ was computed as $(\mathrm{SMM} /$ weight $(\mathrm{kg}) \times$ 100), to determine relative sarcopenia, after calculation of SMM as above from DXA-derived ASM. ${ }^{35}$ Three categories of sarcopenia were defined; normal if $\mathrm{ASM} / \mathrm{ht}^{2}$ or $\mathrm{SMI} \%$ were $<1 \mathrm{SD}$ from the mean of the young reference group; class I sarcopenia if the index fell between $>1 \mathrm{SD}$ and $<2$ $\mathrm{SD}$; and class II sarcopenia if the index was $<2 \mathrm{SD}$ below the mean for the young reference group. ${ }^{8}$

\section{Other covariates}

Age (in years) was calculated as the difference between the date of examination and date of birth. Comorbidity was defined as the number of current chronic conditions based on medical record report of cardiovascular disease, stroke, cancer, diabetes, arthritis, kidney disease, or lung disease. A registered nurse recorded disease conditions from the medical records maintained at each facility.

\section{Data analysis}

Data were analysed using SPSS for Windows (Version 16; SPSS Australasia Ltd, Melbourne, Australia). Continuous data were checked for normality, outlying scores, and missing data. Nonnormal data were transformed and outliers transformed to one unit above/below the next most extreme score. Descriptive data are given as the mean \pm SD or as percentages. Differences between groups were tested via Student's unpaired $t$-test, differences for categorical data were tested via the $\chi^{2}$ test and relationships among variables were examined using Pearson's correlation. As missing values occurred at random (as indicated by Little's $\chi^{2}$ test), missing data points were estimated by an expectation maximization algorithm, ${ }^{36}$ before undertaking multivariate analyses. A value of $P<0.05$ was taken as significant.

\section{Results}

All 63 elderly study participants were ambulatory although $56 \%$ had arthritis. Cardiovascular disease, lung disease, and 
renal disease were present in 38\%, $11 \%$, and $8 \%$, respectively, while $13 \%$ had previously had cancer and $6 \%$ had diabetes. None of the women had GP-diagnosed active cancer at the time of assessment. Medical conditions were found not to be associated with age, body composition, strength, or physical functioning (data not shown). The body composition of these elderly women was compared to that of a young, healthy female reference population (Table 1).

Although body weight did not differ, the elderly were significantly shorter $(P<0.001)$ and had higher mean BMI $(P<0.001)$, lower LTM $(P<0.001)$, but higher total FM $(P<0.01)$. ASM $/ \mathrm{ht}^{2}$ was similar to that of the younger women indicating that their lower level of LTM supported a similar weight but a higher FM. In contrast, $\mathrm{SMI} \%$ was significantly lower in older women $(P<0.001)$. Table 1 also provides strength and function measures for the elderly group. Here, those above the median age of 86 years had significantly lower strength, WS, and TUG than younger elderly (all $P<0.01$, data not shown).

The mean ASM $/ \mathrm{ht}^{2}$ for the young reference group was $6.31 \pm 0.73 \mathrm{~kg} / \mathrm{m}^{2}$ yielding cut-off values for normal ASM $/ \mathrm{ht}^{2}$, class I, and class II sarcopenia of $>5.58 \mathrm{~kg} / \mathrm{m}^{2}, 4.85-5.58 \mathrm{~kg} /$ $\mathrm{m}^{2}$, and $<4.85 \mathrm{~kg} / \mathrm{m}^{2}$, respectively. The mean SMI\% for the young reference group was $32.91 \pm 4.56 \%$ providing corre-

Table I Characteristics of elderly institutionalized Australian women compared with a reference group of healthy young Australian women

\begin{tabular}{|c|c|c|}
\hline Variable & $\begin{array}{l}\text { Elderly women } \\
(n=63)\end{array}$ & $\begin{array}{l}\text { Young women } \\
(n=62)\end{array}$ \\
\hline Age (yrs) & $86.4 \pm 5.5^{* *}$ & $28.8 \pm 6.0$ \\
\hline Medical conditions ${ }^{\mathrm{a}}$ & $1.5 \pm 1.0$ & $\mathrm{n} / \mathrm{a}$ \\
\hline Height (m) & $1.53 \pm 0.07 * *$ & $1.65 \pm 0.07$ \\
\hline Weight (kg) & $62.1 \pm 11.1$ & $61.5 \pm 11.2$ \\
\hline BMI $\left(\mathrm{kg} / \mathrm{m}^{2}\right)$ & $26.7 \pm 4.5^{* *}$ & $22.5 \pm 3.4$ \\
\hline Total fat (kg) & $23.2 \pm 8.4^{*}$ & $17.9 \pm 8.5$ \\
\hline Leg LTM (kg) & $\mathrm{II} . \mathrm{I} \pm \mathrm{I} .8^{* *}$ & $13.3 \pm 2.1$ \\
\hline ASM $(k g)$ & $14.4 \pm 2.1 * *$ & $17.3 \pm 2.8$ \\
\hline LTM (kg) & $35.7 \pm 4.3 * *$ & $40.3 \pm 5.3$ \\
\hline SMM & $15.5 \pm 2.4 * *$ & $20.0 \pm 3.2$ \\
\hline $\mathrm{ASM} / \mathrm{ht}^{2}$ & $6.20 \pm 0.87$ & $6.31 \pm 0.73$ \\
\hline SMI\% & $25.31 \pm 3.51 * *$ & $32.91 \pm 4.56$ \\
\hline Ankle dorsiflexor strength $(\mathrm{N} / \mathrm{kg})$ & $1.59 \pm 0.48$ & $\mathrm{n} / \mathrm{a}$ \\
\hline Knee extensor strength $(\mathrm{N} / \mathrm{kg})$ & $1.46 \pm 0.46$ & $\mathrm{n} / \mathrm{a}$ \\
\hline Hip abductor strength (N/kg) & $1.45 \pm 0.44$ & $\mathrm{n} / \mathrm{a}$ \\
\hline Walking speed (m/second) & $0.67 \pm 0.2$ & $\mathrm{n} / \mathrm{a}$ \\
\hline Timed up and go (seconds) & $17.5 \pm 5.9$ & $\mathrm{n} / \mathrm{a}$ \\
\hline
\end{tabular}

Notes: Data are mean \pm SD. $* P<0.01$; $* * P<0.001$. a Medical conditions confined to those listed in Methods.

Abbreviations: ASM, appendicular skeletal muscle mass; BMI, body mass index; $\mathrm{ht}^{2}$, height squared; LTM, lean soft-tissue mass; SMM, skeletal muscle mass; n/a, not applicable; SMI\%, skeletal muscle mass index (\%). sponding cut-off values for normal $\mathrm{SMI} \%$, class I, and class II sarcopenia of $>28.4 \%, 23.8 \%-28.4 \%$, and $<23.8 \%$, respectively. Table 2 shows the proportion of the elderly population categorized according to these cut-off values.

Figure 1 compares the prevalence of absolute $\left(\mathrm{ASM} / \mathrm{ht}^{2}\right)$ versus relative (SMI\%) sarcopenia according to BMI. Only $3.2 \%$ of the women were underweight, $38.1 \%$ were of normal weight, $39.7 \%$ were overweight while $19 \%$ were obese. Defining sarcopenia by $\mathrm{ASM} / \mathrm{ht}^{2}$ identified few women $(3.2 \%)$ as sarcopenic, all of whom were lean, with a mean BMI of $24.4 \mathrm{~kg} / \mathrm{m}^{2}$. Defining sarcopenia with $\mathrm{SMI} \%$ identified more women $(36.5 \%)$, the majority of whom were overweight or obese, with a mean BMI of $29.1 \mathrm{~kg} / \mathrm{m}^{2}$. Absolute sarcopenia was prevalent in significantly more lean women $(P<0.001)$, whilst relative sarcopenia was more prevalent in overweight and obese women $(P<0.01)$.

The two measures of physical function used in this study TUG and WS, were strongly related to each other $(r=0.699$, $P<0.001)$. Age-adjusted relationships between these two function outcomes and measures of body composition and sarcopenia are presented in Table 3.

TUG and WS were most strongly associated with hip abductor strength $(r=-0.42, P<0.01$ and $r=0.47$, $P<0.001$, respectively). While both measures were also associated with ankle dorsiflexor strength $(r=-0.31$, and $r=0.34$, both $P<0.05$, respectively), only WS was related to knee extensor strength $(r=-0.23, P<0.05)$. Neither TUG nor WS were found to be related to any measures of body composition. TUG also showed an unexpected positive association with absolute sarcopenia $(r=0.28, P<0.05)$.

Women with the highest physical function (in the tertile with shortest TUG and quickest WS) were next compared with women with the poorest physical function (the tertile with longest TUG and slowest WS) (Table 4).

The women with poor physical function were significantly older $(P<0.01)$ and had significantly lower strength mea-

Table 2 Proportion of elderly institutionalized Australian women categorized according to different body composition indices $(n=63)$

\begin{tabular}{ll}
\hline Indices & Percentage (\%) \\
\hline ASM $/ \mathrm{ht}^{2}\left(\mathrm{~kg} / \mathrm{m}^{2}\right)$ & 71.4 \\
Normal & 25.4 \\
Class I sarcopenia & 3.2 \\
Class II sarcopenia & \\
SMl\% $(\mathrm{kg} / \mathrm{kg} \times 100)$ & 20.6 \\
Normal & 42.9 \\
Class I sarcopenia & 36.5 \\
Class II sarcopenia & \\
\hline
\end{tabular}

Abbreviations: ASM, appendicular skeletal muscle mass; $\mathrm{ht}^{2}$, height squared; SMI\%, skeletal muscle mass index (\%). 
A

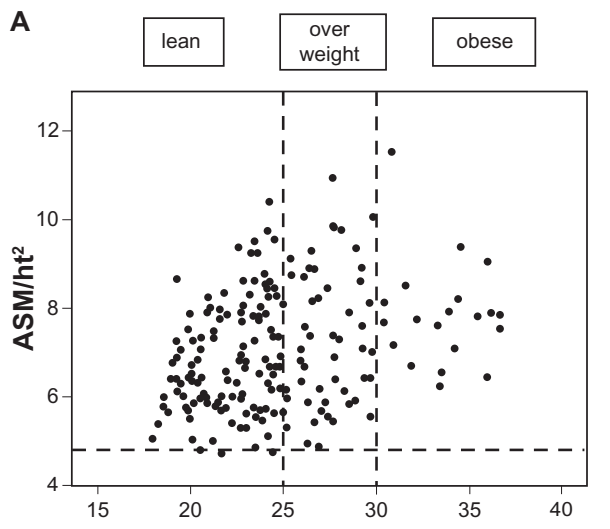

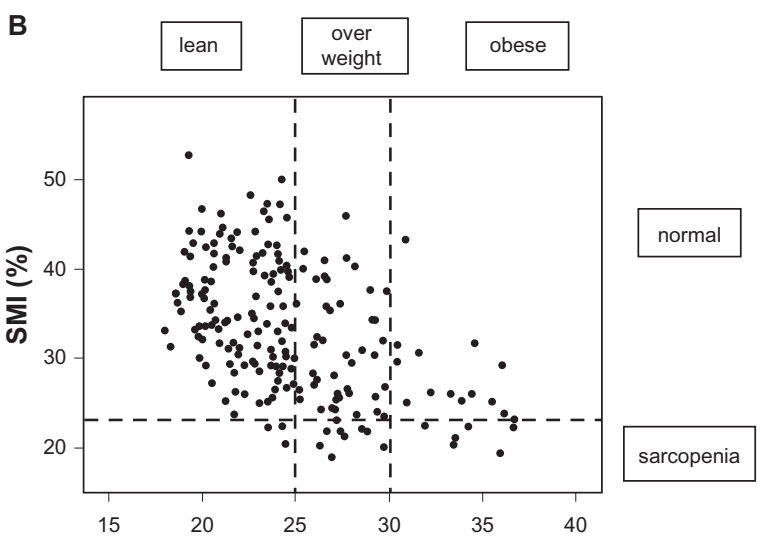

Body mass index $\left(\mathrm{kg} / \mathrm{m}^{2}\right)$

Figure I ASM/ht ${ }^{2}$ (A) or SMI\% (B) in lean (BMI < 25.0), overweight (BMI 25.0-29.9) and obese (BMI $\geq 30$ ) in elderly women in low-level care. Abbreviations: ASM, appendicular skeletal muscle mass; BMI, body mass index; SMI\%, skeletal muscle mass index (\%).

sures at each site $(P<0.05$ at ankle and knee; $P<0.01$ at the hip). There were however, no differences in BMI, SMI, or measures of body composition between the two groups. ASM/ $\mathrm{ht}^{2}$ was significantly higher $(P<0.05)$ in the women with poor physical function consistent with the weak positive relationship found between ASM/ht ${ }^{2}$ and TUG (Table 3). Yet the higher ASM $/ \mathrm{ht}^{2}$ in the women with poor physical function did not reflect significant difference in ASM but rather appeared related to differences in body height since women with poor physical function tended to be shorter $(P=0.07)$.

In a multivariate model including ankle, knee, and hip measures of strength, only hip abductor strength predicted TUG and WS (both $P \leq 0.05$ ), explaining 6.6\% and 7.3\% of the variation respectively (Model A, Table 5). Addition

Table 3 Relationship between measures of physical function and strength with measures of body composition and sarcopenia in elderly institutionalized Australian women $(n=63)$. Data show Pearson's correlations. Relationships have been adjusted for age

\begin{tabular}{lll}
\hline Parameter & $\begin{array}{l}\text { Timed up and } \\
\text { go }(\mathrm{sec})\end{array}$ & $\begin{array}{l}\text { Walking speed } \\
(\mathrm{m} / \mathrm{sec})\end{array}$ \\
\hline $\begin{array}{l}\text { Ankle dorsiflexor strength } \\
(\mathrm{N} / \mathrm{kg})\end{array}$ & $-0.31^{*}$ & $0.34^{*}$ \\
Knee extensor strength & -0.22 & \\
$(\mathrm{~N} / \mathrm{kg})$ & & $0.23^{*}$ \\
Hip abductor strength & $-0.42^{* *}$ & $0.47^{* * *}$ \\
$(\mathrm{~N} / \mathrm{kg})$ & & \\
Weight $(\mathrm{kg})$ & 0.13 & -0.05 \\
Total fat $(\mathrm{kg})$ & 0.08 & 0.003 \\
Total LTM $(\mathrm{kg})$ & 0.15 & -0.08 \\
ASM $/ \mathrm{ht}^{2}\left(\mathrm{~kg} / \mathrm{m}^{2}\right)$ & $0.28^{*}$ & -0.12 \\
SMl\% & -0.001 & 0.03 \\
\hline
\end{tabular}

Notes: $* P<0.05 ; * * P<0.01 ; * * * P<0.001$.

Abbreviations: ASM, appendicular skeletal muscle mass; $\mathrm{ht}^{2}$, height squared; LTM, lean soft-tissue mass; SMI\%, skeletal muscle mass index (\%). of age and LTM (model B) resulted in a small increase in the total $R^{2}$ value of the model: for TUG, $R^{2}$ increased from $19 \%-25 \%(P<0.01)$ while for WS, $R^{2}$ increased from $22 \%-28 \%(P<0.01)$. Again, the only statistically significant strength measure was that of the hip abductors, explaining $10.3 \%$ of the variation in TUG and $10.5 \%$ of the variation in WS (both $P=0.01$, Model B, Table 5). Age

Table 4 Elderly women with good physical function compared to poor physical function ${ }^{\mathrm{a}}$

\begin{tabular}{lll}
\hline Variable & $\begin{array}{l}\text { Good physical } \\
\text { function }(\mathbf{n}=\mathbf{~ I 5})\end{array}$ & $\begin{array}{l}\text { Poor physical } \\
\text { function }(\mathbf{n}=\mathbf{~ I 0})\end{array}$ \\
\hline ASM/ht ${ }^{2}$ & $5.82 \pm 0.76$ & $6.57 \pm 0.95^{*}$ \\
SMI\% & $25.4 \pm 4.0$ & $25.4 \pm 4.6$ \\
Age (yrs) & $84.5 \pm 4.3$ & $90.0 \pm 3.6^{* *}$ \\
Height (m) & $1.56 \pm 6.7$ & $1.51 \pm 4.8$ \\
BMI (kg/m $\left.{ }^{2}\right)$ & $25.1 \pm 4.3$ & $28.0 \pm 4.7$ \\
Ankle dorsiflexor & $1.87 \pm 0.53$ & $1.33 \pm 0.50^{*}$ \\
strength (N/kg) & & \\
Knee extensor & $1.69 \pm 0.67$ & $1.26 \pm 0.23^{*}$ \\
strength (N/kg) & & $1.31 \pm 0.31^{* *}$ \\
Hip abductor & $1.82 \pm 0.53$ & \\
strength (N/kg) & & $23.7 \pm 10.5$ \\
Total fat (kg) & $22.8 \pm 9.0$ & $36.8 \pm 4.8$ \\
LTM (kg) & $35.0 \pm 2.4$ & $15.0 \pm 2.4$ \\
ASM (kg) & $14.0 \pm 1.4$ & $11.6 \pm 2.1$ \\
Leg LTM (kg) & $10.7 \pm 1.2$ & $0.46 \pm 0.08^{* * *}$ \\
Walking speed & $0.94 \pm 0.12$ & \\
(m/second) & & $25.6 \pm 2.8^{* * *}$ \\
Timed up and go & $10.5 \pm 2.3$ & \\
(seconds) & &
\end{tabular}

Notes: Data are mean \pm SD. $* P<0.05 ; * * P<0.01$; $* * * P<0.001$. aWomen with good physical function were in the lowest tertile for TUG and the highest tertile for WS while women with poor physical function were in the highest tertile for TUG and the lowest tertile for WS.

Abbreviations: ASM, appendicular skeletal muscle mass; BMI, body mass index; $\mathrm{ht}^{2}$, height squared; LTM, lean soft-tissue mass; SMI\%, skeletal muscle mass index (\%). 
Table 5 Relationships between muscle strength and TUG or WS explored in a multivariate model

\begin{tabular}{|c|c|c|c|c|c|c|c|c|}
\hline \multirow{2}{*}{$\frac{\text { Measure }}{\text { Model A }}$} & \multicolumn{4}{|c|}{ Timed up and go (sec) } & \multicolumn{4}{|c|}{ Walking speed $(\mathrm{m} / \mathrm{min})$} \\
\hline & \multirow{2}{*}{\multicolumn{3}{|c|}{0.19}} & \multirow{2}{*}{\multicolumn{4}{|c|}{0.22}} & \\
\hline Total model $R^{2}$ & & & & & & & & \\
\hline$P$-value & \multicolumn{3}{|c|}{0.005} & \multicolumn{4}{|c|}{0.002} & \\
\hline Independent variable & B & $P$ & $\begin{array}{l}\text { Variation } \\
\text { explained }^{a}\end{array}$ & $\mathbf{C l}$ & B & $P$ & $\begin{array}{l}\text { Variation } \\
\text { explained }^{\mathrm{a}}\end{array}$ & $\mathbf{C l}$ \\
\hline Ankle dorsiflexor strength $(\mathrm{N} / \mathrm{kg})$ & -0.14 & 0.40 & 1.2 & -5.6 to 2.3 & 0.17 & 0.29 & 1.9 & -0.06 to 0.2 \\
\hline Knee extensor strength $(\mathrm{N} / \mathrm{kg})$ & 0.03 & 0.83 & 0.08 & -3.6 to 4.4 & -0.06 & 0.69 & 0.3 & -0.16 to 0.11 \\
\hline Hip abductor strength (N/kg) & 0.36 & 0.05 & 6.6 & -9.5 to -0.1 & 0.37 & 0.04 & 7.3 & 0.01 to 0.32 \\
\hline \multicolumn{9}{|l|}{ Model B } \\
\hline Total model $R^{2}$ & \multicolumn{3}{|c|}{0.25} & \multicolumn{4}{|c|}{0.28} & \\
\hline$P$-value & \multicolumn{3}{|c|}{0.004} & \multicolumn{4}{|c|}{0.002} & \\
\hline Independent variable & B & $P$ & $\begin{array}{l}\text { Variation } \\
\text { explained }^{\mathrm{a}}\end{array}$ & $\mathbf{C l}$ & B & $P$ & $\begin{array}{l}\text { Variation } \\
\text { explained }^{\mathrm{a}}\end{array}$ & $\mathbf{C l}$ \\
\hline Ankle dorsiflexor strength $(\mathrm{N} / \mathrm{kg})$ & 0.03 & 0.86 & 0.05 & -4.4 to 3.7 & 0.06 & 0.73 & 0.2 & -0.11 to 0.16 \\
\hline Knee extensor strength $(\mathrm{N} / \mathrm{kg})$ & 0.10 & 0.52 & 0.7 & -2.7 to 5.4 & -0.11 & 0.49 & 0.8 & -0.18 to 0.09 \\
\hline Hip abductor strength $(\mathrm{N} / \mathrm{kg})$ & -0.46 & 0.01 & 10.3 & -10.9 to -1.3 & 0.46 & 0.01 & 10.5 & 0.05 to 0.36 \\
\hline Age (years) & 0.21 & 0.08 & 5.1 & -0.3 to 0.5 & -0.27 & 0.03 & 8.2 & -0.02 to -0.001 \\
\hline $\operatorname{LTM}(\mathrm{kg})$ & 0.17 & 0.17 & 3.2 & -0.1 to 0.5 & -0.07 & 0.55 & 0.6 & -0.01 to 0.01 \\
\hline
\end{tabular}

Notes: apercentage of variation explained uniquely by the independent variable after adjustment.

Abbreviations: ASM, appendicular skeletal muscle mass; BMI, body mass index; CI, 95\% confidence interval; ht ${ }^{2}$, height squared; LTM, lean soft-tissue mass; SMM, skeletal muscle mass; n/a, not applicable; SMI\%, skeletal muscle mass index (\%); TUG, timed up and go; WS, walking speed.

was a predictor of WS $(P<0.05)$ and also tended to predict TUG $(P=0.08)$ while LTM was not a predictor of physical function. In further analyses, both absolute and relative sarcopenia indices were also not predictors of physical function (data not shown).

\section{Discussion}

This study examines sarcopenia and physical function in elderly Australian women living in low-level aged care. Two common indices of sarcopenia, $\mathrm{ASM} / \mathrm{ht}^{2}$ and $\mathrm{SMI} \%$ defined different populations. Only ASM/ht ${ }^{2}$ showed any association with physical function (TUG, Table 3 ) and this association was weak, in an unexpected positive direction and might be explained by differences in body height (Table 4). Elderly women were shorter than younger women, possibly as a result of vertebral compression following reduced bone mineral density. ${ }^{37}$ Comparisons between women of high versus poor physical function indicated clear differences in ankle, knee, and especially hip strength but none in body composition (Table 4). Moreover, hip strength was a significant predictor of physical function. Hip strength therefore appears to be a more important indicator of physical function in this population than measures of muscle quantity (defined by LTM or sarcopenic indices).

Our population of elderly women had clearly different body composition from the young women used as a reference group. These differences of reduced muscle mass, increased FM, and increased percentage total fat are consistent with previous reports. ${ }^{2,3,38}$ Additionally, the relatively high prevalence of overweight and obesity in our elderly women was comparable with that seen in other elderly women residing at home ${ }^{39,40}$ or in aged care. ${ }^{41}$ Their low LTM was also similar to that found in healthy community-dwelling elderly women. ${ }^{42}$

The reported prevalence of sarcopenia in elderly populations differs with age and gender, the definition of sarcopenia applied and the normative data used for comparison. We compared the absolute method of Baumgartner ${ }^{7}$ with the relative method of Janssen. ${ }^{8}$ In the absence of universally accepted reference ranges ${ }^{42}$ and the presence of ethnic differences, ${ }^{43}$ cut-off values should be selected from an ethnically similar, local reference population who have been measured in a similar way, using a similar DXA scanner. ${ }^{44}$ The use of Australian reference data from a population with similar height and weight to the general Australian Caucasian population, ${ }^{45}$ is one strength of our study. In contrast, reference populations used by Baumgartner ${ }^{7}$ and Janssen ${ }^{8}$ included African Americans and Mexican Americans who differ in LTM, ${ }^{4,46}$ and infrequently live in Australia. Among other reference populations, ${ }^{7,8,40}$ only those from Italy ${ }^{40}$ align with those we report here, which justifies the application of our own cutoffs for sarcopenia. 
Reported prevalence of sarcopenia in elderly populations ranges from 5\%-50\%. ${ }^{47}$ Applying Australian cut-off values, $3.2 \%$ of our elderly women had absolute sarcopenia. This is lower than in America or in Europe where prevalence ranges between $16 \%-43 \% \%^{3,48,49}$ and $9.5 \%-12.3 \%,{ }^{2,38,50}$ respectively. In addition, $42.9 \%$ of our elderly women had relative sarcopenia, class I, while $36.5 \%$ had relative sarcopenia, class II. The prevalence of class II sarcopenia is higher than the $10 \%$ reported by Janssen ${ }^{8}$ or the $21 \%$ approximated from Estrada. ${ }^{49}$ Our data are also consistent with Estrada's finding that relative and absolute measures of sarcopenia define two distinct populations, ${ }^{49}$ with absolute sarcopenia more common in lean women and relative sarcopenia more common in overweight or obese women. Where obesity is present the relative measure appears more physiologically and clinically relevant since it is better at detecting reduction in mobility. ${ }^{49}$

Poor physical function can be defined by TUG $>12$ seconds. ${ }^{20}$ In our study, $73 \%$ of women had TUG $>12$ seconds, intermediate between the prevalence of $91 \%$ reported for institutionalized mobile women, and $8 \%$ reported for community dwelling elderly women. ${ }^{20} \mathrm{WS}$ also indicates poor physical function in elderly populations and is predictive of adverse outcomes: those with WS $<0.6 \mathrm{~m} / \mathrm{sec}$ are at increased risk of functional decline and death. ${ }^{19}$ In our elderly population, $43 \%$ of women had WS $<0.6 \mathrm{~m} / \mathrm{sec}$. Mean WS was $0.67 \mathrm{~m} / \mathrm{sec}$, appreciably slower than for community dwelling, elderly Australians where the mean WS was $0.99 \mathrm{~m} / \mathrm{sec}^{26}{ }^{2}$ Our results therefore suggest that institutionalized women in low-level care have poorer physical function than women who reside in the community. This is not surprising given that institutionalized women have been assessed as requiring additional care, however, it does signal a higher risk of adverse outcomes and the need for programs to improve physical functioning.

Absolute sarcopenia has been associated with limited physical function in some,,${ }^{7,81}$ but not all, ${ }^{40,50}$ cases where physical function has been measured by self-report. When physical function was measured objectively, ${ }^{49}$ little association between absolute sarcopenia and physical function has been evident. In contrast, a relationship between relative sarcopenia and limited physical function has been found regardless of whether physical function was selfreported ${ }^{7,8,40,51}$ or measured objectively. ${ }^{49}$ In our study, absolute sarcopenia was weakly associated only with TUG but not with WS, while relative sarcopenia was unrelated to either measure (Table 3). The discrepancy with findings in the literature may relate to over- or under-estimation of functional ability with self-reported measures,${ }^{52}$ or may be due to exclusion of some possible confounders when analyses have been performed.

Measures of muscle mass have also been shown to be predictive of muscle function ${ }^{11,12,53}$ although the association is no longer observed after adjustment for muscle strength. ${ }^{11,12}$ In contrast we found no association between LTM or any other measure of body composition and TUG or WS. Decreased strength, as measured by either knee extensors/ flexors or hand grip strength has been associated with worse physical function, ${ }^{9,11,12,53-55}$ and in all cases except one, ${ }^{53}$ muscle mass has been found to be a nonsignificant variable compared with muscle strength. Indeed, Visser has concluded that underlying muscle strength can explain any association between muscle mass and physical function. ${ }^{11,12}$ Most previous studies however, have targeted generally healthy, higher functioning elderly of less advanced age making comparison with our functionally limited, older group difficult.

In our study, the most important variables related to physical function (as assessed by TUG and WS) were ankle, knee, and particularly hip strength (Table 4). In multivariate analyses, only hip abductor strength predicted physical function (although age also predicted WS). Most previous studies assessing leg strength and physical function have used knee extensor/flexor and/or ankle dorsiflexor strength as a proxy for lower extremity strength..$^{55}$ Few report the contribution made by differing muscle groups to physical function. Here we assess the strength of three different muscle groups, finding that whilst strength in each group was associated with function in univariate analysis, once all measures were taken into account, only hip abductors were significantly associated with function. All three muscle groups examined are important for normal gait and strength deficiencies in any group affect gait and gait speed. Poor hip abductor strength affects pelvic stabilization, allowing tilting of the pelvis along with slowing of gait. ${ }^{56}$ Hip extensors also appear particularly important for the activities of daily living. ${ }^{27}$ The dominant effect of hip strength as reported here has not always been apparent in earlier studies. For example, in one study, strength of hip extensors and abductors was only weakly associated with gait speed and the ability to rise from a chair, although when these measures were combined with measures of leg and ankle strength, and normalized for weight, significant associations with performance emerged. ${ }^{56}$ Conditions of loading may have affected these findings. Another study reported that the strength of hip flexors and knee extensors only predicted physical function under conditions of a light load ( $<15 \mathrm{~kg}$ and $<10 \mathrm{~kg}$, respectively; neither normalized to weight). ${ }^{57}$ Rantanen however, 
in an examination of WS in disabled elderly women, found a load threshold affected knee extensor strength only and not hip flexor strength. ${ }^{58}$ No other published studies have assessed hip abductor strength and physical function. Further studies discriminating between specific muscle groups and describing their relative importance in maintaining function in the elderly are therefore now needed.

The strong relationship between strength and physical function evident in our study indicates the importance of maintaining strength in elderly women. Progressive resistance strength training can achieve this. ${ }^{59,60}$ Resistance programs recommended for elderly people usually continue for 8-12 weeks with high intensity exercise 2-3 times per week. As possible adverse effects remain poorly documented, care must be taken in planning and implementing such programs. Nonetheless, resistance training has been used successfully in a group of institutionalized nonagenarians. ${ }^{61}$ At present, the Accreditation Standards for Aged Care in Australia make no recommendation for exercise programs or resistance training. ${ }^{62}$

A number of limitations in this study need to be acknowledged. The study is cross-sectional in nature, so causality cannot be imputed. It was also based on a relatively small sample in which those incapable of self consent were not included. Nevertheless, it is the first study to describe body composition by DXA in elderly women in low-level residential care, to estimate the prevalence of sarcopenia by different indices, and to describe the relationships among body composition, muscle strength of different muscle groups, and objectively measured physical function.

In conclusion, this study shows similar body composition parameters and prevalence of sarcopenia, but poorer physical functioning, in elderly women in low-level care to those reported for community-dwelling elderly women. It also demonstrates that in these elderly women, hip strength is a better predictor of physical function rather than muscle mass. As muscle mass and sarcopenic indices were unrelated to physical function, measurement of muscle mass seems an inappropriate screening tool to detect physical function limitations or requirements for additional care in this elderly group. This is consistent with the absence of muscle mass as a criterion to identify frailty in one screening tool. ${ }^{63}$ Measurement of muscle strength predicted physical functioning in our present study is clinically simple to perform and appears a better screening tool than muscle mass for an elderly population. Further longitudinal studies in this group using a range of strength measures and taking into account physical activity ${ }^{64}$ and fitness are now warranted.

\section{Acknowledgments}

We would like to thank the staff and residents of the agedcare facilities and the young reference group members for their cooperation and participation in the study. We would also like to acknowledge research nurses Sheila Matthews, Judy Tan, and Kylie King who sourced medical data on residents and Bereha Khorda for performing muscle strength testing. Shea Edsall's help with initial analyses on the two groups is also appreciated. The larger trial in which this study was nested was funded by Dairy Australia.

\section{Disclosure}

No conflicts of interest were declared in relation to this paper.

\section{References}

1. Seidell JC, Visscher TL. Body weight and weight change and their health implications for the elderly. Eur J Clin Nutr. 2000;54 Suppl 3: S33-S39.

2. Kyle UG, Genton L, Hans D, Karsegard L, Slosman DO, Pichard C. Age-related differences in fat-free mass, skeletal muscle, body cell mass and fat mass between 18 and 94 years. Eur J Clin Nutr. 2001; 55(8):663-672.

3. Baumgartner RN, Stauber PM, McHugh D, Koehler KM, Garry PJ. Cross-sectional age differences in body composition in persons 60+ years of age. J Gerontol A Biol Sci Med Sci. 1995;50(6):M307-M316.

4. Gallagher D, Visser M, De Meersman RE, et al. Appendicular skeletal muscle mass: effects of age, gender, and ethnicity. J Appl Physiol. 1997; 83(1):229-239.

5. Roubenoff R, Hughes VA. Sarcopenia: current concepts. J Gerontol A Biol Sci Med Sci. Dec 2000;55(12):M716-M724.

6. Thomas D. Loss of skeletal muscle mass in aging: examining the relationship of starvation, sarcopenia and cachexia. Clin Nutr. 2007; 26(4):389-399.

7. Baumgartner RN, Koehler KM, Gallagher D, et al. Epidemiology of sarcopenia among the elderly in New Mexico. Am J Epidemiol. 1998; 147(8):755-763.

8. Janssen I, Heymsfield SB, Ross R. Low relative skeletal muscle mass (sarcopenia) in older persons is associated with functional impairment and physical disability. J Am Geriatr Soc. 2002;50(5):889-896.

9. Goodpaster BH, Park SW, Harris TB, et al. The loss of skeletal muscle strength, mass, and quality in older adults: the Health, Aging and Body Composition Study. J Gerontol A Biol Sci Med Sci. 2006; $61 \mathrm{~A}(10): 1059$.

10. Hughes VA, Frontera WR, Wood M, et al. Longitudinal muscle strength changes in older adults: influence of muscle mass, physical activity, and health. J Gerontol A Biol Sci Med Sci. 2001;56A(5):B209.

11. Visser M, Goodpaster BH, Kritchevsky SB, et al. Muscle mass, muscle strength, and muscle fat infiltration as predictors of incident mobility limitations in well-functioning older persons. J Gerontol A Biol Sci Med Sci. 2005;60A(3):324.

12. Visser M, Deeg DJ, Lips P, Harris TB, Bouter LM. Skeletal muscle mass and muscle strength in relation to lower-extremity performance in older men and women. J Am Geriatr Soc. 2000;48(4):381-386.

13. Newman AB, Kupelian V, Visser M, et al. Strength, but not muscle mass, is associated with mortality in the Health, Aging and Body Composition Study cohort. J Gerontol A Biol Sci Med Sci. 2006;61A(1):72.

14. Bauer JM, Kaiser M, Sieber CC. Sarcopenia in nursing home residents. J Am Med Dir Assoc. 2008;9(8):545-551. 
15. Australian Institute of Health and Welfare. Residential Aged Care in Australia 2005-06: A Statistical Overview. Aged Care Statistics Series nr 24 Cat. No. AGE 54. Canberra: AIHW; 2007.

16. Woods JL, Walker KZ, Iuliano-Burns S, Strauss BJ. Malnutrition on the menu: nutritional status of institutionalised elderly Australians in low-level care. J Nutr Health Aging. 2009;13(8):693-698.

17. Kendig H, Browning C, Pedlow R, Wells Y, Thomas S. Health, social and lifestyle factors in entry to residential aged care: an Australian longitudinal analysis. Age Ageing. 2010;39(3):342-349.

18. Podsiadlo D, Richardson S. The timed up and go: a test of basic functional mobility for frail elderly persons. J Am Geriatr Soc. 1991; 39(2):142-148.

19. Abellan Van Kan G, Rolland Y, Andrieu S, et al. Gait speed at usual pace as a predictor of adverse outcomes in community-dwelling people: an International Academy on Nutrition and Aging (IANA) taskforce. J Nutr Health Aging. 2009;13(10):881-889.

20. Bischoff HA, Stahelin HB, Monsch AU, et al. Identifying a cut-off point for normal mobility: comparison of the timed 'up and go' test in community dwelling and institutionalised elderly women. Age Ageing. 2003;32(3):315-320.

21. Bohannon RW. Reference values for the timed up and go test: a descriptive meta-analysis. J Geriatr Phys Ther. 2006;29(2):64-68.

22. Cruz-Jentoft AJ, Baeyens JP, Bauer JM, et al. Sarcopenia: European consensus on definition and diagnosis: report of the European working group on sarcopenia in older people. Age Ageing. 2010; 39(4):412-423.

23. Woodrow G. Body composition analysis techniques in the aged adult: implications and limitations. Curr Opin in Clin Nutr Metab Care. 2009; 12(1):8-14.

24. Department of Health and Ageing. Aged Care in Australia. Canberra: Commonwealth of Australia; 2006.

25. King SJ, Nyulasi IB, Strauss B, Kotsimbos T, Baioley M, Wilson JW. Fat-free mass depletion in adult cystic fibrosis is associated with lung disease severity but is poorly detected by body mass index. Nutrition. 2010;26(7-8):753-759.

26. Hill K, Schwarz J, Flicker L, Carroll S. Falls among healthy, community-dwelling, older women: a prospective study of frequency, circumstances, consequences and prediction accuracy. Aust NZ J Public Health. 1999;23(1):41-48.

27. Hasegawa R, Islam M, Sung Chul L, Koizumi D, Rogers M, Takeshima N. Threshold of lower body muscular strength necessary to perform ADL independently in community-dwelling older adults. Clin Rehabil. 2008; 22(10-11):902.

28. Cleophas TJ, Zwinderman AH, Cleophas TF, Cleophas EP. Statistics Applied to Clinical Trials. Berlin, Germany: Springer; 2009.

29. Shrawan K. Muscle strength. Boca Raton, FL: CRC Press; 2004.

30. Arnold C, Warkentin K, Chilibeck P, Magnus C. The reliability and validity of handheld dynamometry for the measurement of lowerextremity muscle strength in older adults. J Strength Cond Res. 2010; 24(3):815-824.

31. Plank LD. Dual-energy X-ray absorptiometry and body composition. Curr Opin Clin Nutr Metab Care. 2005;8(3):305-309.

32. Genton L, Hans D, Kyle UG, Pichard C. Dual-energy X-ray absorptiometry and body composition: differences between devices and comparison with reference methods. Nutrition. 2002;18(1): 66-70.

33. Hull H, He Q, Thornton J, Javed F, Allen L, Wang J, et al. iDXA, Prodigy, and DPXL Dual-energy X-ray absorptiometry whole-body scans: a cross-calibration study. J Clin Densitom. 2009;12(1):95-102.

34. Heymsfield SB, Smith R, Aulet M, et al. Appendicular skeletal muscle mass: measurement by dual-photon absorptiometry. Am J Clin Nutr. 1990;52(2):214-218.

35. Kim J, Wang Z, Heymsfield SB, Baumgartner RN, Gallagher D. Totalbody skeletal muscle mass: estimation by a new dual-energy X-ray absorptiometry method. Am J Clin Nutr. 2002;76(2):378-383.

36. Tabachnick BG, Fidell LS. Using multivariate statistics. 5th ed. Boston, MA: Pearson International; 2007.
37. Briot K, Legrand E, Pouchain D, Monnier S, Roux C. Accuracy of patient-reported height loss and risk factors for height loss among postmenopausal women. Can Med Assoc J. 2010;182(6):558-562.

38. Gillette-Guyonnet S, Nourhashemi F, Andrieu S, et al. Body composition in French women 75+ years of age: the EPIDOS study. Mech Ageing Dev. 2003;124(3):311-316.

39. Krahnstoever Davison K, Ford ES, Cogswell ME, Dietz WH. Percentage of body fat and body mass index are associated with mobility limitations in people aged 70 and older from NHANES III. JAm Geriatr Soc. 2002; 50(11):1802-1809.

40. Zoico E, Di Francesco V, Guralnik J, et al. Physical disability and muscular strength in relation to obesity and different body composition indexes in a sample of healthy elderly women. Int J Obes (Lond). 2004; 28(2):234-241.

41. Grieger JA, Nowson CA, Ackland M. Anthropometric and biochemical markers for nutritional risk among residents within an Australian residential care facility. Asia Pac J Clin Nutr. 2007;16(1):178-186.

42. Schutz Y, Kyle UG, Pichard C. Fat-free mass index and fat mass index percentiles in Caucasians aged 18-98 y. Int J Obes Relat Metab Disord. 2002;26(7):953-960.

43. Kyle UG, Genton L, Lukaski HC, et al. Comparison of fat-free mass and body fat in Swiss and American adults. Nutrition. 2005; 21(2):161-169.

44. Van der Sluis IM, de Ridder MA, Boot AM, Krenning EP, de Muinck Keizer-Schrama SM. Reference data for bone density and body composition measured with dual-energy $\mathrm{X}$ ray absorptiometry in white children and young adults. Arch Dis Child. 2002;87(4):341-346.

45. Australian Bureau of Statistics. National Nutrition Survey. Nutrient intakes and physical measurements. Australia 1995. Canberra, Australia: Commonwealth of Australia; 1998.

46. Travison TG, Araujo AB, Esche GR, McKinlay JB. The relationship between body composition and bone mineral content: threshold effects in a racially and ethnically diverse group of men. Osteoporos Int. 2008; 19(1):29-38.

47. Morley J. Sarcopenia: diagnosis and treatment. J Nutr Health Aging. 2008;12(7):452-456.

48. Morley JE. Anorexia, body composition, and ageing. Curr Opin Clin Nutr Metab Care. 2001;4(1):9-13.

49. Estrada M, Kleppinger A, Judge JO, Walsh SJ, Kuchel GA. Functional impact of relative versus absolute sarcopenia in healthy older women. JAm Geriatr Soc. 2007;55(11):1712-1719.

50. Rolland Y, Lauwers-Cances V, Cournot M, et al. Sarcopenia, calf circumference, and physical function of elderly women: a cross-sectional study. J Am Geriatr Soc. 2003;51(8):1120-1124.

51. Melton LJ III, Khosla S, Crowson CS, O'Connor MK, O'Fallon WM, Riggs BL. Epidemiology of sarcopenia. J Am Geriatr Soc. 2000; 48(6):625-630.

52. Guralnik JM, Simonsick EM, Ferrucci L, et al. A short physical performance battery assessing lower extremity function: association with self-reported disability and prediction of mortality and nursing home admission. J Gerontol. 1994;49(2):M85-M94.

53. Reid K, Naumova E, Carabello R, Phillips E, Fielding R. Lower extremity muscle mass predicts functional performance in mobilitylimited elders. J Nutr Health Aging. 2008;12(7):493.

54. Visser M, Newman AB, Nevitt M, et al. Reexamining the sarcopenia hypothesis. Muscle mass versus muscle strength. Ann N Y Acad Sci. 2000;904:456-461.

55. Lauretani F, Russo CR, Bandinelli S, et al. Age-associated changes in skeletal muscles and their effect on mobility: an operational diagnosis of sarcopenia. J Appl Physiol. 2003;95(5):1851-1860.

56. Brown M, Sinacore DR, Host HH. The relationship of strength to function in the older adult. J Gerontol A Biol Sci Med Sci. 1995; 50A:55-59.

57. Ferrucci L, Guralnik JM, Buchner D, et al. Departures from linearity in the relationship between measures of muscular strength and physical performance of the lower extremities: the Women's Health and Aging Study. J Gerontol A Biol Sci Med Sci. 1997;52A(5):M275-M285. 
58. Rantanen T, Guralnik JM, Izmirlian G, et al. Association of muscle strength with maximum walking speed in disabled older women. Am J Phys Med Rehabil. 1998;77(4):299-305.

59. Latham NK, Bennett DA, Stretton CM, Anderson CS. Systematic review of progressive resistance strength training in older adults. J Gerontol A Biol Sci Med Sci. 2004;59A(1):48.

60. Liu C-J, Latham NK. Progressive resistance strength training for improving physical function in older adults. Cochrane Database Syst Rev. 2009;8(3):CD002759.

61. Fiatarone MA, Marks EC, Ryan ND, Meredith CN, Lipsitz LA, Evans WJ. High-intensity strength training in nonagenarians: effects on skeletal muscle. JAMA. 1990;263(22):3029-3034.
62. Office of Legislative Drafting and Publishing. Quality of Care Principles 1997. Canberra, Australia: The Attorney-General's Department; 2010.

63. Fried LP, Tangen CM, Walston J, Newman AB. Frailty in older adults: evidence for a phenotype. J Gerontol A Biol Sci Med Sci. 2001; 56A(3):M146-M156.

64. Koster A, Visser M, Simonsick EM, et al. Association between fitness and changes in body composition and muscle strength. J Am Geriatr Soc.58(2):219-226.

\section{Publish your work in this journal}

Clinical Interventions in Aging is an international, peer-reviewed journal focusing on evidence-based reports on the value or lack thereof of treatments intended to prevent or delay the onset of maladaptive correlates of aging in human beings. This journal is indexed on PubMed Central, MedLine, the American Chemical Society's 'Chemical Abstracts
Service' (CAS), Scopus and the Elsevier Bibliographic databases. The manuscript management system is completely online and includes a very quick and fair peer-review system, which is all easy to use. Visit http://www.dovepress.com/testimonials.php to read real quotes from published authors.

Submit your manuscript here: http://www.dovepress.com/clinical-interventions-in-aging-journal 